\title{
Awareness and Willingness to Pay for Community Based Health Insurance Scheme in North-Western Nigeria
}

\author{
Giwa Abdulganiyu PhD ${ }^{l}$, Kabir Muhammad MSc ${ }^{2}$,Umar Ibrahim MSc ${ }^{3}$, Suleiman H.H. PhD ${ }^{4}$, Lawal B.K MSc ${ }^{5}$
}

\begin{abstract}
There is a need for the communities to develop their health financing system, most especially those that were not covered by the National Health Insurance Scheme (NHIS). This will give the people an opportunity to finance their medical care which in turn would alleviate financial burden at the point of treatment. Therefore, this study is aimed to determine the level of awareness for Community Based Health Insurance Scheme (CBHIS) among communities and to measure the degree of willingness to pay for the scheme in Katsina, North-Western Nigeria. Semi structured interviewer-assisted questionnaires were used to collect information from the respondents. Statistical analyses were performed using SPSS version 20.0. The results indicates that majority of the respondents attained tertiary level of education (68.3\%) and $81.1 \%$ were employed. About $74.2 \%$ were earning more than the Nigerian minimum wage N18, $000(\approx \$ 59)$. About $52.2 \%$ of the respondents were aware of the CBHIS. And $81 \%$ were willing to pay for premium while $62.2 \%$ will pay between $\mathrm{N} 1,000-5,000(\approx \$ 3.3-$ \$16.4). There was strong significant relationship between monthly income and knowledge of CBHIS ( $\mathrm{p}=<0.0001)$. However, gender and educational level were not significantly associated with the knowledge of CBHIS. Awareness about CBHIS was not sufficiently adequate but a significant number of the respondents were willing to pay for CBHIS after learning about the scheme. Factors such as level of education and income levels were found to have positive effect on willingness to pay.
\end{abstract}

Keywords: Willingness to pay (WTP); Awareness; Community Based Health insurance; Healthcare financing; Household head 1 USD $\equiv 305.70$ NGN (Nigeria Currency) $(\$ 1 \equiv N 305.70)$

\section{Introduction}

Out of pocket payment for healthcare which dominates Nigerian healthcare systems bring about a serious barrier to health service seeking behavior in Nigeria ${ }^{[1]}$. Healthcare is quite costly, and only the wealthier among the people can afford to pay the costs of treating a serious illness when it arise. Community-based health insurance scheme pools the risk of high care costs across a large number of people, permitting them to pay a premium based on the average cost of medical care for the group of people. This risk-spreading function helps make the cost of health care reasonably affordable for most people ${ }^{[2]}$.

A recent review of health-system financing for Universal Health Coverage in Nigeria shows high out-of-pocket

\footnotetext{
1. Department of Clinical Pharmacy and Pharmacy Practice, Faculty of Pharmaceutical Sciences. University of Ilorin, Nigeria.

2. Department of Pharmacy, School of Health Technology, Kankia. College of Health Sciences and Technology, Katsina

3. Department of Clinical Pharmacy and Pharmacy Administration, Faculty of Pharmaceutical Sciences Bayero University, Kano

4. Department of Economics, Faculty of Social and Management Sciences. Bayero University Kano

5. Department of Clinical Pharmacy and Pharmacy Management, Faculty of Pharmaceutical Sciences, Kaduna State University

Address of correspondence: Kabir Muhammad

Department of Pharmacy, School of Health Technology, Kankia.

College of Health Sciences and Technology, Katsina

E-mail:mhmmdkabir@gmail.com
}

expenses for health care, a very low budget for health at all levels of government, and poor health insurance penetration ${ }^{[3 / 4]}$. According to WHO, general government expenditure on health as a percentage of total government expenditure was very low at $3 \cdot 3 \%$ in 2002 , increasing consistently per year to $9 \cdot 4 \%$ in 2007 and dropped to $6 \cdot 7 \%$ in $2012^{[5]}$. Private expenditure on health as a percentage of total health expenditure remains high, dropping slightly from $74.4 \%$ in 2002 to $68.9 \%$ in 2012. Out-of-pocket expenditure as a percentage of private expenditure on health has consistently remained higher than $90 \%$ since 2002 , and was $95 \cdot 7 \%$ in $2012^{[6]}$.

Health related risks pose a greatest threat to households as it directly affects lives and livelihood. The uncertainties associated with the untimely illness, its huge treatment costs make financial provision difficult for households ${ }^{[7]}$. There is a rapid change and increase in medical expenditure most especially on some infectious diseases like malaria and chronic diseases like hypertension and Diabetes mellitus plus family's consumption. This bring about the need for the communities most especially those that were not covered by the National health insurance scheme (NHIS) to develop their health financing system ${ }^{[8]}$. This will give the people an opportunity to finance their medical care so that they can alleviate financial burden at the point of treatment. Health insurance actually gives partial reimbursement to the people for expenditure on selected diseases ${ }^{[9]}$.

Unfortunately, there is little knowledge to complete ignorance about the community based health insurance scheme in the whole North-Western Nigeria and there is no institute in the region. Therefore, this study aimed to determine the level of

Bangladesh Journal of Medical Education 2018;9(2):19-23. C 2018 Abdulganiyu et al., publisher and licensee Association for Medical Education.

This is an Open Access article which permits unrestricted non-commercial use, provided the original work is properly cited. 
awareness for community based health insurance and to measure the degree of willingness to pay for the scheme in Katsina State, North-Western Nigeria in 2016.

\section{Method}

\section{Ethical consideration}

Participation in this study was voluntary and consent was sought from the respondents before filling the questionnaire. No findings which could identify individual respondents were published.

\section{Study Site/ Population and sample size}

Dutsin safe low-cost housing estate is one of the earliest estates in the ancient city of Katsina, North-Western Nigeria. The housing estate was built by the then Kaduna State government and completed in 1988. It comprises of two, three and four bedroom semi-detached houses in units of twos. The study population were mainly household heads resident in Dutsin safe low cost area of Katsina metropolis.

Since CBHIS is targeted towards communities, the whole of the Dutsen safe community (180 households) was sampled and recruited for the study.

Sample size : 180

\section{Inclusion criteria}

All household heads (male and female) above 18 years old resident in Dutsin safe low-costs housing estate.

Any adult above the age of 18 years old available when the household head is not around and is a permanent resident of the area.

\section{Exclusion criteria}

All households that are not permanent resident of Dutsin safe low cost housing estate.

Households below the age of 18 years old.

\section{StudyDesign}

This was a cross-sectional study in which data was collected using a combined close-ended/open-ended interviewer/selfadministered questionnaire (semi-structured). SingleBounded Dichotomous Choice (SBDC) approach was used in the study where respondents in the survey were usually presented with one bid amount to which they can respond with either a yes or no to show their willingness to pay or not to pay ${ }^{[10]}$. The questionnaire basically contained three basic sections adequate to capture relevant data required. These sections captured information on the demographic and socioeconomic characteristics of the households, CBHIS awareness and willingness to pay.

A pilot study was carried out with 10 subjects randomly selected from the study area. From the pilot study, respondents were found to be able to understand and answer the questionnaire provided. Consequently, no further modification of the questionnaire was done prior to the actual survey.

\section{Statistical Analysis}

Data was analyzed using Statistical Package for Social Sciences. All demographic data were analyzed descriptively and presented as frequencies and percentages. Chi-square analysis was carried out between CBHIS awareness and willingness to pay with the socio-economic characteristics (gender, education levels and income) to test for significance.

\section{Results}

\section{Socio-demographic characteristics of the respondents}

Summary of the socio-demographic characteristics of the respondents was shown in Table 1. A total of 180 respondents participated in the study. Majority were males $(82.8 \%)$. Most were married $(86.7 \%)$ and were between the ages of 26-35 (27.8\%). Majority attained tertiary level of education $(68.3 \%)$ and about $81.1 \%$ were employed (worked for pay and self-employed). Slightly more than a quarter $(25.8 \%)$ were earning less than $\$ 65(\mathrm{~N} 20,000)$ and most of them have 4-6 children $(26.7 \%)$.

Table 1: Socio-Demographic Characteristics of the Respondents $(\mathrm{n}=180)$

\begin{tabular}{|c|c|c|}
\hline & Frequency & Percentage $(\%)$ \\
\hline \multicolumn{3}{|l|}{ Gender } \\
\hline Male & 149 & 82.8 \\
\hline Female & 31 & 17.2 \\
\hline \multicolumn{3}{|l|}{ Age } \\
\hline $18-25$ & 46 & 25.6 \\
\hline $26-35$ & 50 & 27.8 \\
\hline $36-45$ & 44 & 24.4 \\
\hline $46-55$ & 23 & 12.8 \\
\hline Above 55 & 17 & 9.4 \\
\hline \multicolumn{3}{|l|}{ Marital Status } \\
\hline Married & 156 & 86.7 \\
\hline Single & 21 & 11.7 \\
\hline Divorced/Widowed & 3 & 1.7 \\
\hline \multicolumn{3}{|l|}{ Level of Education } \\
\hline Tertiary Education & 123 & 68.3 \\
\hline Secondary Education & 36 & 20.0 \\
\hline Primary Education & 1 & 0.6 \\
\hline Informal Education & 12 & 6.7 \\
\hline Others & 8 & 4.4 \\
\hline \multicolumn{3}{|l|}{ Employment Level } \\
\hline Employed & 146 & 81.1 \\
\hline Unemployed & 34 & 18.9 \\
\hline \multicolumn{3}{|c|}{ Monthly household income (\$) } \\
\hline$<\$ 65$ & 46 & 25.8 \\
\hline$\$ 66-\$ 654$ & 85 & 47.8 \\
\hline$\$ 655$ and above & 47 & 26.4 \\
\hline \multicolumn{3}{|l|}{ Number of children } \\
\hline None & 21 & 11.7 \\
\hline 1-3 children & 48 & 26.8 \\
\hline 4-6 children & 46 & 25.7 \\
\hline 7-9 children & 34 & 19.0 \\
\hline 10 and above & 30 & 16.8 \\
\hline
\end{tabular}

Bangladesh Journal of Medical Education 2018;9(2):19-23. 
Knowledge and Willingness to pay for Community Based Health Insurance Scheme Slightly more than half $(52.2 \%)$ have knowledge about CBHIS while $68.9 \%$ indicated interest to participate. About $81 \%$ were willing to pay for premium while $65.2 \%$ will pay between the ranges of approx. \$3.3-\$16.4 (N 1, 000-5, 000).

Table 2: Knowledge and willingness to pay for community based health insurance scheme (CBHIS) $(n=180)$

\begin{tabular}{lcc}
\hline Item & Frequency & Percentage \\
\hline Knowledge of CBHIS & & \\
Yes & 94 & 52.2 \\
No & 86 & 47.8 \\
Interest to participate & & \\
Yes & 124 & 68.9 \\
No & 56 & 31.2 \\
Willingness to pay premium & & \\
Yes & 146 & 81.1 \\
No & 34 & 18.9 \\
Willingness to pay between $\approx \mathbf{\$ 3 . 3}$ & $\mathbf{- \$ 1 6 . 4}(\mathbf{N 1 0 0 0}-\mathbf{N 5 0 0 0})$ \\
Yes & 117 & 65.2 \\
No & 59 & 32.80 \\
\hline
\end{tabular}

Relationship between knowledge of CBHIS and socio-demographic characteristics of the respondents

There was significant relationship between monthly income and knowledge of CBHIS $(p=<0.0001)$. However, gender and educational level were not significantly associated with the knowledge of CBHIS.

Table 3: Relationship between CBHIS Awareness and Demographic Characteristics of the Respondents $(\mathrm{n}=180)$

\begin{tabular}{lcccc}
\hline Variable & \multicolumn{2}{c}{ Awareness } & & \\
& No & Yes & $\mathbf{X}^{2}(\mathbf{d f})$ & p-value \\
\hline $\begin{array}{l}\text { Gender } \\
\text { Male }\end{array}$ & $110(80.9)$ & $39(88.6)$ & $1.402(1)$ & 0.236 \\
Female & $26(19.1)$ & $5(11.4)$ & & \\
$\begin{array}{l}\text { Educational level } \\
\text { Tertiary }\end{array}$ & $91(66.9)$ & $32(72.7)$ & $0.520(1)$ & 0.471 \\
Below Tertiary & $45(33.1)$ & $12(27.3)$ & & \\
Monthly Income & & & & \\
$\leq \$ 65(\mathrm{~N} 20,000)$ & $44(32.8)$ & $2(4.5)$ & $13.833(1)$ & 0.000 \\
$>\$ 65(\mathrm{~N} \mathrm{20,000)}$ & $90(67.2)$ & $42(95.5)$ & & \\
\hline
\end{tabular}

\section{Relationship between Willing To Pay (WTF) and socio-demographic characteristics of the respondents}

Gender was found to be significantly associated with WTP $(\mathrm{p}=0.001)$ with more males $(87.7 \%)$ were willing to pay than females (12.3\%). WTP was found not to be associated with Educational level and monthly income but a trend was observed that respondent that attained tertiary level of education were more willing to pay. Additionally, those with monthly income of above NGN 20. 000 were also more willing to pay.

Table 4: Relation between WTP and the demographic characteristics of the respondents $(\mathrm{n}=180)$

\begin{tabular}{lcccc}
\hline Variable & \multicolumn{2}{c}{ Awareness } & & \\
& No & Yes & $\mathbf{X}^{2}(\mathbf{d f})$ & p-value \\
\hline $\begin{array}{l}\text { Gender } \\
\text { Male }\end{array}$ & $21(63.6)$ & $128(87.7)$ & $11.145(1)$ & 0.001 \\
$\begin{array}{l}\text { Female } \\
\text { Educational level } \\
\text { Tertiary }\end{array}$ & $20(60.6)$ & $18(12.3)$ & & \\
$\begin{array}{l}\text { Below Tertiary } \\
\text { Monthly Income }\end{array}$ & $13(39.4)$ & $43(29.5)$ & & \\
$\leq \$ 65(\mathrm{~N} \mathrm{20,000)}$ & $14(43.8)$ & $31(21.4)$ & $6.919(1)$ & 0.009 \\
$>$ \$65 (N 20, 000) & $18(56.2)$ & $114(78.6)$ & & \\
\hline
\end{tabular}

\section{Discussion}

The results obtained from the study shows that there were more male respondents $149(82.8 \%)$ than females $(17.2 \%)$ indicating more male household heads/respondents which is a characteristic of typical Hausa community. Most of the respondents were married $(86.7 \%)$ and $68.3 \%$ of the respondents attained a tertiary level of education. This is also an anticipated result since Dutsin-safe is at the urban center of Katsina and the Nigerian urban communities are characterized by high literacy levels. It was discovered that $81.1 \%$ of the respondents were employed with $74.2 \%$ earning more than N20,000 (\$65) monthly.

CBHIS is a relatively new concept of healthcare financing, which was developed to provide financial risk protection for the low-income households, the poor and the vulnerable groups ${ }^{[1]}$. Awareness and knowledge about CBHIS is of prime importance before the commencement of the scheme. Community Based Health Insurance Scheme is not popular in Nigeria, and it is still not fully implemented even in the developing countries that have massively started the scheme ${ }^{[11]}$. In this study, there was generally poor level of awareness among the households. The households that attained a tertiary level literacy have higher level of awareness about CBHIS when compared with the households with a lower level literacy, but there was a very considerable proportion of tertiary level literates (103 of 123 ) i.e. 83.7\% that were willing to pay for community based health insurance scheme while secondary level literates have $77.1 \%$ willingness to pay. Therefore, there was a positive correlation between literacy levels and willingness to pay in the present study. Dror, Redermacher and Koren (2007) ${ }^{[12]}$ has reported a positive relationship between educational attainment and willingness to pay which is similar to findings in the current study.

Gender was identified as a factor for WTP as 128 out of 149 males were willing to pay $(87.7 \%)$ while only 18 out of 30 females were willing to pay $(12.3 \%)$ or it can be $60 \%$. Male household heads more willing to pay and more willing to pay higher amounts when compared with female household

Bangladesh Journal of Medical Education 2018;9(2):19-23. 
heads. This is consistent with the findings by David Mark, Radermacher, \& Koren, 2007; and Tundui \& Macha (2014) who found that male household heads were more willing to purchase and pay for health insurance than the female household heads ${ }^{[1][13]}$.

Slightly more than half of the respondents $(52.2 \%)$ were aware of CBHIS with $124(69.3 \%)$ interested in participating in the scheme and $146(81.6 \%)$ willing to pay for the scheme. This finding is similar to result obtained from a comparative study among rural and urban households on willingness to pay for CBHI carried out in Osun state by Usman and Bukola (2013) where the results indicated that $82.8 \%$ of the rural households were willing to pay for CBHIS ${ }^{[14]}$. However, a lower score $(51.6 \%)$ was obtained from the urban households which contradicts the findings obtained from the current study conducted in an urban area. This study revealed that about $78.6 \%$ household heads were earning slightly above the current National Minimum Wage of N18, $000(\approx \$ 59)$ as average monthly income, which suggest that socioeconomic status may influence the willingness to pay. The affluent among the people were anticipated to be more willing to pay than the poor. This is because, the affluent are more conscious about their health and well-being which may also affect their productivity. CBHIS is therefore, more suitable for rural settlers and poor persons as opined by Usman and Bukola (2013) in Southwestern Nigeria; and David Mark, Radermacher, and Koren (2007) in rural areas of India ${ }^{[14][15]}$. Poor people are vulnerable to diseases and catastrophic spending at the point of healthcare intervention. Moreover, Garba, Harun, and Salihu (2015) found a correlation between socioeconomic status and willingness to pay for CBHIS among the rural dwellers in Sokoto, Northwestern Nigeria ${ }^{[16]}$.

Moreover, Onwujekwe, Uzochukwu, and Kirigia, (2011) investigated the basis for effective CBHIS in the Southeastern Nigeria and found that in addition to Income levels of the people, the premium for the scheme should be affordable to the people ${ }^{[17]}$. In the present study, $65.2 \%$ of household head were willing to pay a premium of about $\approx$ $\$ 3.3-\$ 16.4(\mathrm{~N} 1,000$ to $\mathrm{N} 5,000)$. This indicates that majority of the households can afford to purchase the insurance premium. However, the most-poor among the people could not afford to pay for the premium no matter how cheap, this will negatively affects the CBHIS coverage. CBHIS is targeted towards the poor, vulnerable and people that were not covered by any form of Insurance (Informal sector). Thus, there should be solidarity and altruism among the people in the community. The wealthy among the people should pay higher premium to cover for the less privileged among the community. As philanthropy is generally related to wealth, Onwujekwe, Uzochukwu, and Kirigia (2011) also found a positive correlation between socioeconomic status, altruism and willingness to pay for CBHIS and opined that the poor have to depend on the altruistic contributions from the affluent in the community to be able to enroll in CBHIS, as they may not afford the full premium ${ }^{[17]}$.

In spite of the important factors that influence WTP for CBHIS explored in this study, there are other equally important factors which needs to be explored; such as social capital, trust, community participation in setting-up, management, maintenance and sustenance of the scheme. Social capital is important factor to consider in setting-up a CBHIS. Herman, Pythogore, Donfouet, Pirre, and Alexandret (2012) studion community based health insurance and social capital in rural areas of developing countries reported a positive and significant association between social capital of the communities and willingness to participate in and pay for community based health insurance scheme ${ }^{[18]}$. Since CBHIS targets communities, there should be an existing communal networks, relationship, association or corporation and solidarities among the people in the community to own it.

In the present study, a significant number of the respondents were willing to pay for community based health insurance scheme. The respondents were able to understand the relevance and importance of CBHIS. A number of factors were identified to influence willingness to pay. These factors include but not limited to level of education and income levels which positively have effect on willingness to pay. As far my knowledge this study was the first of its kind to be carried out in Nigeria area, therefore, there are a lot of untapped prospective research gaps that need to be filled in this field of study. Aspects such as socioeconomic status, Affordability, and Social capital issues with CBHIS are potential areas for further research.

\section{Conclusion}

There was significant relationship between monthly income and knowledge of CBHIS. However, gender and educational level were not significantly associated with the knowledge of CBHIS. Awareness about community based health insurance scheme was not sufficiently adequate and a significant number of the respondents were willing to pay for community based health insurance scheme. Factors such as level of education and income levels were found to have positive effect on willingness to pay.

\section{Acknowledgements}

The cooperation of the Settlements' head, Household head, Household members and entire community members of Dutsen-Safe is hereby acknowledged.

\section{References}

1. Aboyomi Samuel Oyekale. Factors influencing households' willingness to pay for National Health Insurance scheme (NHIS) in Osun state, Nigeria. Ethno Med, 2012.6(3): 167-172

2. Gary Caxton. How private insurance works: Institution for healthcare research and policy, Georgetown University, on behalf of Henry J. Kaiser family foundation. 2002Updated 2008

3. Lancet global health - Nigeria's new government and public financing for universal health coverage http://www.thelancet.com/journals/langlo/article/PIIS

Bangladesh Journal of Medical Education 2018;9(2):19-23. 
2214-109X(15)00088-1/fulltext?rss=yes Accessed August 2015

4. Uzochukwu B, Ughasoro, MD, Etiaba, E, Okwuosa, C, Envuladu, E, and Onwujekwe, OE. Health care financing in Nigeria: implications for achieving universal health coverage. Niger J Clin Pract.2015; 18: 437-444

5. WHO. Global Health Observatory Data Repository. Nigeria: statistics summary (2002-present).http:// apps.who.int/ gho/data/node.country.country-NGA Accessed August 2015

6. Towards achieving universal health coverage in Nigeria -Business day http://businessdayonline.com/2014/06/ towards-achieving-universal-health-coverage-innigeria/ Accessed August 23, 2015

7. Arhin-Tenkorang, D. Health insurance for the informal sector in Africa: Design features, risk protecttion, and resource mobilization. CMH Working paper series, paper no WG3:2001. Washington DC. (www.cmhealth.org/ docs/wg3_paper 1.pdf)

8. Onwujekwe, O., Uzochukwu, B., Ezeoke, O., \& Uguru, $\mathrm{N}$. Health Insurance: principles, models and the Nigerian National Health Insurance Scheme. Journal of College of Medicine, 2012.16(1), 45-56. https:// doi.org/10.4314/jcm.v16i1.8

9. Maumita Ghosh. Awareness and willingness to pay for health insurance: A study of Darjeeling district. IOSR Journal of humanities and social science (IOSR-JHSS) Volume 12, issue 1 (May-Jun 2013), PP 41-47 e-ISSN: 2279-0837, p-ISSN: 2279-0845. (www.iosrjournals.org)

10. Dror, D., \& Koren, R. The elusive quest for estimates of willingness to pay for health microinsurance. In $\mathrm{C}$. Churchill \& M. Matul (Eds.), protecting the poor: A microinsurance compendium (Vol. II, pp: 156-173) 2012. Geneva, Switzerland: International Labour Office.

11. Carrin, G., Waelkens, M.-P., \& Criel, B. Communitybased health insurance in developing countries: a study of its contribution to the performance of health financing systems. Tropical Medicine and International Health, 2005. 10(8), 799-811. https://doi.org/10.1111/ j. 1365-3156.2005.01455.x
12. Dror DM, Radermacher R, Koren R. Willingness to pay Health Insurance Units in India. Field evidence from seven micro health insurance units in India. Health Policy 2007. 82: 176-181

13. Tundui, C., \& Macha, R. Social Capital and Willingness to Pay for Community Based Health Insurance: Empirical Evidence from Rural Tanzania. Journal of Finance and Economics, 2014. 2(4), 50-67. https://doi.org/10.12735/jfe.v2i4p50

14. Usman, \& Bukola, A. Willingness to Pay For Community Based Health Care Financing Scheme: A Comparative Study among Rural and Urban Households in Osun State, Nigeria. IOSR Journal of Dental and Medical Sciences, 2013. 5(6), 2279-861. Retrieved from www.iosrjournals.org

15. David Mark, D., Radermacher, R., \& Koren, R. Willingness to pay for health insurance among rural and poor persons: Field evidence from seven micro health insurance units in India. Health Policy, 2007. 82(1), 12-27. https://doi.org/10.1016/j.healthpol. 2006.07.011

16. Garba, I., Harun, A., \& Salihu, A. A. The Way forward for Community-Based Health Insurance Scheme in Funding Health Care among the Rural Communities of Sokoto State, Nigeria. Online), 2015. 5(8), 2225-484.

17. Onwujekwe, O., Uzochukwu, B., \& Kirigia, J. Basis for effective CBHI schemes: investigating inequities in catastrophic out-of-pocket health expenditures, affordability and altruism. African Journal of Health Economics, 2011.1-11.

18. Hermann Pirre Pythogore Donfouet, Pirre Alexandre Mahieu. Community based health insurance and social capital: a review: Donfouet and Mahieu Health Economics Review 2012, 2:5 http://www. healtheconomicsreview.com/content/2/1/5

Bangladesh Journal of Medical Education 2018;9(2):19-23. 